\title{
A Day-Ahead Optimal Economic Dispatch Schedule for Building CCHP System Based on Centralized Energy Storage Infrastructure
}

\author{
Zeng Aidong ${ }^{1}$, Hao Sipeng ${ }^{1}$, Xu Qingshan ${ }^{2}$, Liu Yujun ${ }^{2}$, Huang $\mathrm{Yu}^{2}$ \\ ${ }^{1}$ School of Electric Power Engineering, Nanjing Institute of Technology, \\ No. 1 Hongjing Avenue, Jiangning District, Nanjing, China \\ ${ }^{2}$ School of Electrical Engineering, Southeast University, \\ No.2 Sipailou Road, Xuanwu District, Nanjing, China \\ zengaidong@njit.edu.cn
}

\begin{abstract}
This paper proposes a day-ahead optimal economic dispatch model for building Combined Cooling, Heat and Power (CCHP) system based on centralized energy storage infrastructure. In the model, the loads are met by the centralized energy storage equipment directly, and the storage equipment are charged by varieties of energy supply devices in the energy station of the building CCHP system. The model is solved by the interior point method with Hessian matrix iteration. Simulation results show that by performing the schedule made by the dispatch model, the storage status of the centralized energy storage fluctuates in large dynamic range by flexible charging and discharging and the daily operation cost of the building CCHP system decreases remarkably compared with other traditional schedule strategies.
\end{abstract}

Index Terms-Combined cooling, heat and power; CCHP; Centralized energy storage infrastructure; Interior point method; Optimal economic dispatch.

\section{INTRODUCTION}

Building Combined Cooling, Heat and Power (CCHP) system contains four kinds of energy forms: cold, heat, electricity and gas, and has become an important means to improve energy utilization efficiency, solve energy shortage and environmental pollution issues by its high energy consumption efficiency, flexible and reliable energy supply mode [1], [2].

Currently in practical applications, the construction of building CCHP system is still under preliminary stage wherein some of the well-known applications are the project University of California, Davis (UCD) and University of New Mexico (UNM) [3]. In theory research, a commercial building energy supply system model with the goal of minimum operating costs was built and solved by CPLEX in [4]. A two-stage energy management strategy for CCHP microgrid is proposed by Luo Z, et al. [5], and Z. X. Yuan et

Manuscript received 19 September, 2017; accepted 10 May, 2018

This research was funded by University Natural Science Research Major Project of Jiangsu Province (No. 17KJA470003); National Natural Science Foundation of China (No.51577028) and High-level Talent Introduction Scientific Research Foundation of Nanjing Institute of Technology (No. YKJ201715). al. designed the economic indicators of CCHP based hybrid energy supply system [6]. In [7], [8], a dispatching model of day-ahead scheduling with the objective of achieving the minimal expected MG operation cost which considered the uncertainty of wind and solar power was established and solved by improved PSO algorithm. In [9], energy level and exergy analysis are implemented on energy conversion processes to reveal the variation of energy amount and quality in the operation of CCHP system. Zheng C Y et al. [10] proposed a thermal storage strategy for CCHP systems to determine the operational state of the power generation unit based upon electric demand, thermal demand and the state of thermal storage device.

This paper researches on the energy supply infrastructure of building CCHP system. Then a day-ahead optimal economic dispatch model of building CCHP system is built based on the infrastructure and solved to make dispatch schedule for improving the economic efficiency of the system.

\section{ENERGY SUPPLY INFRASTRUCTURE OF BUILDING CCHP SYSTEM WITH CENTRALIZED ENERGY STORAGE}

In the energy supply infrastructure, the energy supply and storage equipment include micro turbines, hot water tank, Lithium Bromide refrigeration units, chilled water tank, electrical heater, electrical heating storage tank, battery, and distributed solar system. The building CCHP system exchanges power with external power network, and the gas needed in the system is all bought from the municipal gas company considering that there is no gas production in the building CCHP system.

The building CCHP system produces electricity through the micro turbines, which generate electric power by natural gas. The consequent high temperature flue gas is converted to high temperature steam, which can be used to produce hot water or chilled water by the Lithium Bromide refrigeration units.

In the infrastructure, the loads are satisfied by the centralized energy storage equipment directly instead of the energy supply equipment, and the storage equipment are charged by varieties of energy supply devices. For the cold 
energy supply system, the refrigeration load and space cooling load are satisfied by the chilled water tank, which is charged by the Lithium Bromide refrigeration units. For the heat energy supply system, the hot water load and space heating load are satisfied by the hot water tank, which is charged by the micro turbines and electrical heating storage tank. The energy supply infrastructure of building CCHP systems is shown in Fig. 1.

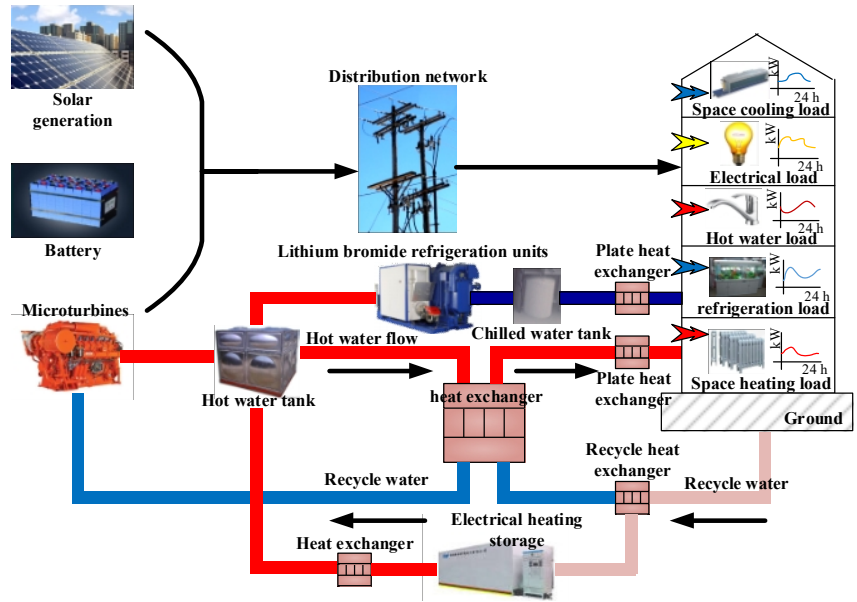

Fig. 1. Energy supply infrastructure of building CCHP system with centralized energy storage.

\section{ENERGY SUPPLY EQUIPMENT OF BUILDING CCHP SYSTEM}

\section{A. Micro Turbines}

Micro turbines are the core equipment in the building CCHP system. In this paper, the energy supply model of micro turbines is established based on Capstone C1000 system [11]-[13]. Capstone C1000 system is a power generation system with characteristics of strong adaptability, low emission and low maintenance cost, which is composed of five Capstone C200 units.

The Capstone C200 unit generates high-frequency AC power through the high-speed rotation of the turbine-driven rotor, and then converts the high-frequency $\mathrm{AC}$ power to $50 \mathrm{~Hz}$ AC power through power electronic devices. The relationship between efficiency (ratio of power output to instant gas energy input) and power output of Capstone C200 unit is shown in Fig. 2.

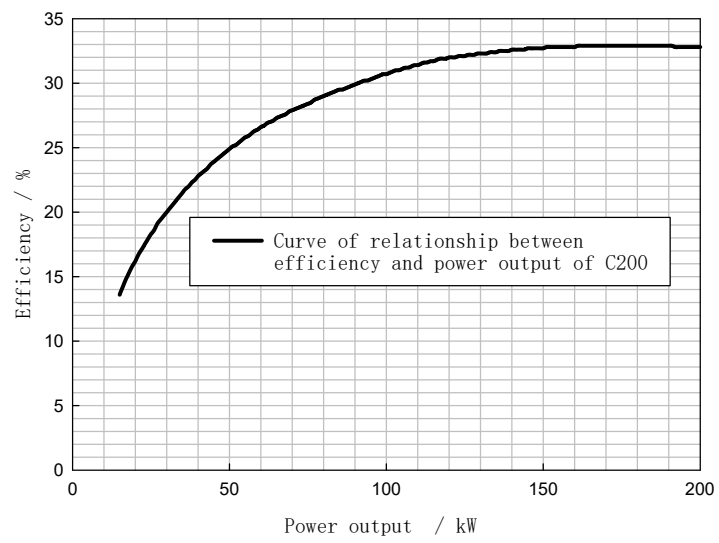

Fig. 2. Curve of the relationship between efficiency and power output of Capstone C200 unit.

Capstone C1000 system automatically selects the number of units to be turned on according to the power generation schedule, the units which have been turned on share the scheduled power generation value averagely, the power generation efficiency and the flexibility are both greatly improved in comparison with merely increasing the unit mass, which owns only one huge rotor and the efficiency curve is exactly the same as the Capstone C200 unit except for the power output. The relationship between efficiency and power output of Capstone C1000 system is shown in Fig. 3.

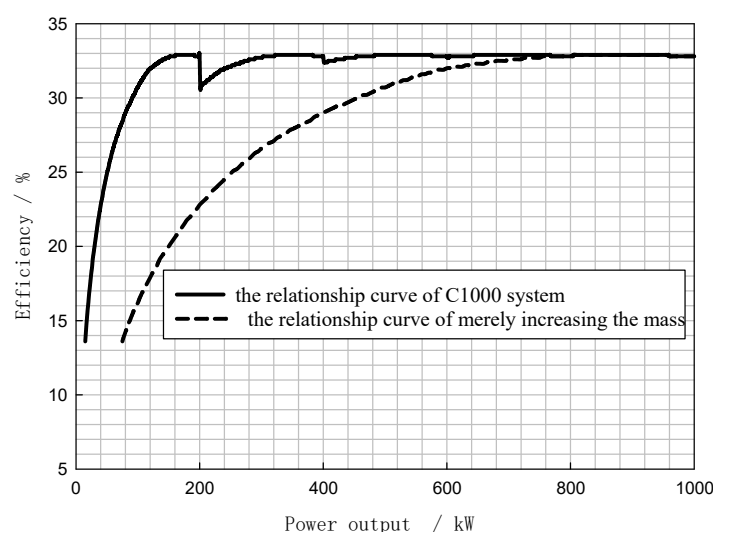

Fig. 3. Curve of the relationship between efficiency and power output of Capstone C1000 system.

Through polynomial fitting, the power output function of Capstone C1000 system is obtained as follows

$$
\eta_{C 1000}=f(P)=\sum_{i=1}^{K} p_{i}\left(\frac{P}{P_{\max }}\right)^{K-i}
$$

where $\eta_{\mathrm{C} 1000}$ is the power generation efficiency at power output $P, P_{\max }$ is the rated power of the system, $f(P)$ is the power output function, $p_{i}$ is the coefficient of function $f(P), K$ is the order of polynomial fitting function.

\section{B. Energy Storage Equipment}

Energy storage equipment plays the role of loads shifting, also relieves the mismatch of cold heat and power ratio between loads and micro turbine systems. The energy storage equipment in the building CCHP system include battery, hot water tank, chilled water tank and electrical heating storage tank.

The characteristics of energy storage equipment contain storage capacity, maximum state of storage, maximum power input and output, energy loss coefficient and storage efficiency [14], [15]. The model of energy storage equipment is represented by the differential equation shown in (2)

$$
\begin{gathered}
S_{\text {stor }}(t+1)=S_{\text {stor }}(t) \times(1-\mu)+ \\
+\left(\eta^{a b s} \times P_{a b s}(t)-\frac{1}{\eta^{\text {relea }}} \times P_{\text {relea }}(t)\right) \times \Delta t,
\end{gathered}
$$

where $S_{\text {stor }}(\mathrm{t})$ and $S_{\text {stor }}(\mathrm{t}+1)$ are the energy existed in the energy storage equipment at moment $t$ and $t+1, \Delta t$ is the interval from moment $t$ to $t+1, P_{a b s}(t)$ is the power input of the energy storage equipment at moment $t, P_{\text {relea }}(t)$ is the power output of the energy storage equipment at moment $t, \mu$ 
is the energy loss coefficient, $\eta_{a b s}$ is the efficiency of energy absorption; $\eta_{\text {relea }}$ is the efficiency of energy release.

\section{Auxiliary Energy Supply Equipment}

The auxiliary energy supply equipment in the building CCHP system include Lithium Bromide refrigeration units and electrical heater. For simplicity, consider the efficiency of the auxiliary energy supply equipment does not change due to the ambient environment, the model of auxiliary energy supply equipment is represented by the linear equation shown in (3)

$$
\eta_{\text {aux }}=\frac{H_{\mathrm{aux}, \mathrm{out}}}{H_{\text {aux }, \text { in }}}
$$

Constraints

$$
0 \leq H_{\text {aux }, \text { out }} \leq H_{\text {aux }, \text { out } \max },
$$

where $H_{\text {aux,out }}$ is the heat(cooling) output of auxiliary energy supply equipment $(\mathrm{kW}), H_{\text {aux, in }}$ is the energy input of auxiliary energy supply equipment $(\mathrm{kW}), \eta_{\text {aux }}$ is the COP (coefficient of performance) of the auxiliary energy supply equipment, $H_{\text {aux outmax }}$ is the maximum heat(cooling) output of the equipment.

\section{Optimal ECONOMIC DisPatch MODEL FOR BUILDING}

The energy station in the building CCHP systems contains many types of energy supply equipment to match the cold, heating and power loads in the building. To achieve the goal of efficient allocation of cooling, heat, electricity and gas, optimal economic dispatch schedule must be made for energy supply and storage equipment in the energy station.

After the modeling of energy supply and storage devices, the optimal economic dispatch model for building CCHP systems is established considering the influences of TOU price. The optimal operation schedule is obtained by solving the dispatch model.

Assumptions of the model are as follows:

1. Output of energy supply and storage equipment is continuous.

2. Equipment failure does not occur during operation periods.

\section{A. Optimization Objective}

The optimization objective is the minimum of daily operation cost of the building CCHP system price, including fuel cost pri $_{\text {fuel }}$, power purchase cost prigrid $_{\text {grid }}$ and equipment maintenance cost primaintain $_{\text {as shown in (5) }}$

$$
\min \text { price }=\min \left(\text { pri }_{\text {fuel }}+\text { pri }_{\text {grid }}+\text { pri } i_{\text {maintain }}\right) \text {. }
$$

\section{1) Fuel cost}

The fuel cost of micro turbine systems is shown in (6)

$$
\operatorname{pri}_{\text {fuel }}=\sum_{t=1}^{24} \sum_{i=1}^{n_{\text {CHP }}} c_{\text {Gas }}^{\mathrm{t}} \times f_{C H P i}\left(P_{i}^{\mathrm{t}}\right) \times \Delta t,
$$

where $f_{C H P i}$ is the consumption characteristic function of $i^{\text {th }}$ micro turbine, $P_{i}^{t}$ is the power output of $\mathrm{i}^{\text {th }}$ micro turbine at moment $\mathrm{t}(\mathrm{kW}), c_{\text {Gas }}^{t}$ is the gas price at moment $\mathrm{t}(\$ / \mathrm{kWh})$.

2) Power purchase cost

The power purchase cost of building CCHP system with the grid is shown in (7)

$$
\operatorname{pri}_{\mathrm{g} r i d}=\sum_{t=1}^{24} c_{\text {Grid }}^{t} \times P_{\text {Grid }}^{t} \times \Delta t,
$$

where $c_{\text {Grid }}^{t}$ is the electricity purchasing price at moment $\mathrm{t}$ (\$/kWh), $P_{\text {Grid }}^{t}$ is the exchange power between building CCHP system and the grid at moment $\mathrm{t}(\mathrm{kW})$.

\section{3) Equipment maintenance cost}

The equipment maintenance cost of building CCHP system is shown in (8)

$$
\begin{gathered}
\text { rri }_{\text {maintain }}=\sum_{t=1}^{24} \sum_{i=1}^{n_{C H P}} p_{m C H P i} \times P_{i}^{\mathrm{t}} \times \Delta t+ \\
+\sum_{t=1}^{24} p_{m E H} \times P_{E H}^{t} \times \Delta t+\sum_{t=1}^{24} p_{\text {mdistri }} \times P_{\text {distri }}^{\mathrm{t}} \times \Delta t+ \\
+\sum_{t=1}^{24} \sum_{i=1}^{n_{\text {stor }}} p_{\text {mstor }}^{i} \times H_{\text {in }}^{i, t} \times \Delta t+\sum_{t=1}^{24} \sum_{i=1}^{n_{\text {stor }}} p_{\text {mstor }}^{i} \times H_{\text {out }}^{i, t} \times \Delta t+ \\
+\sum^{24} p_{m L B R} \times C_{L B R}^{t} \times \Delta t,
\end{gathered}
$$

where $p_{m C H P}, p_{m E H}, p_{m d i s t r}, p_{m s t o r}^{i}, p_{m L B R}$ is the maintenance cost of $\mathrm{i}^{\text {th }}$ micro turbine, electrical heater, distribution generation, $\mathrm{i}^{\text {th }}$ storage device, Lithium Bromide refrigeration units respectively $(\$ / \mathrm{kWh})$, and $P_{i}^{t}, P_{E H}^{t}, P_{\text {distri }}^{t}, C_{L B R}^{t}$ is the power output of $i^{\text {th }}$ micro turbine, electrical heater, distribution generation, Lithium Bromide refrigeration units respectively (kW). $H_{\text {in }}^{i, t}, H_{\text {out }}^{i, t}$ refers to the power input and output of the four kinds of storage devices $(\mathrm{kW})$.

\section{B. Model Constraints}

Constraints of the model include the balance constraints of power, heat and cold energy, capacity constraints and operation constraints of the energy supply and storage equipment.

\section{1) The balance constraint of power}

$$
\sum_{i=1}^{n_{C H P}} P_{i}^{\mathrm{t}}+P_{\text {distri }}^{\mathrm{t}}+P_{\text {Grid }}^{t}+P_{\text {stor }}^{t}=P_{\text {Load }}^{t}+P_{E H}^{t},
$$

where $P_{\text {Grid }}^{t}$ is the exchange power between building CCHP system and the grid at moment $\mathrm{t}(\mathrm{kW}), P_{\text {Load }}^{t}$ is the load at moment $\mathrm{t}(\mathrm{kW}), P_{\text {Stor }}^{t}$ is the net power output of the storage device, $P_{E H}^{t}$ is the power input of electrical heater, $P_{\text {distri }}^{t}$ is the power output of DG, $P_{i}{ }^{t}$ is the power output of $i^{\text {th }}$ micro turbine.

2) The balance constraints of overall heat

The heat energy demand is satisfied by the hot water tank, the balance constraints of overall heat are shown in below:

$$
\begin{gathered}
H_{H W T, \text { out }}^{t}-H_{L B R, \text { in }}^{t} \geq H_{\text {Space }}^{t}+H_{\text {Water }}^{t}, \\
\sum_{i=1}^{n_{C H P}} H_{i}^{\mathrm{t}}+H_{E H S T, \text { out }}^{t}=H_{H W T, \text { in }}^{t},
\end{gathered}
$$


where $H_{i}^{t}$ is the recycling heat of $\mathrm{i}^{\text {th }}$ micro turbine, $H_{E H S T}^{t}$ is the thermal power output of the electrical heater storage tank, $H_{H W T, \text { in }}^{t}$ and $H_{H W T \text {,out }}^{t}$ are the thermal power input and output of the hot water tank respectively, $H_{L B R, i n}^{t}$ is the thermal power input of the Lithium Bromide refrigeration units, $H_{\text {space }}^{t}$ and $H_{\text {water }}^{t}$ are the space heat load and hot water load respectively in the building CCHP system, the variable $H_{H W T, \text { in }}^{t}$ and $H_{H W T, o u t}^{t}$ meets the equipment constraint of (2).

3) The balance constraints of overall cooling

The cooling energy demand is satisfied by the chilled water tank, the balance constraints of overall cooling are shown in (12) and (13):

$$
\begin{gathered}
C_{C W T, \text { out }}^{t} \geq C_{\text {Space }}^{t}+C_{\mathrm{Refri}}^{t}, \\
C_{L B R, \text { out }}^{t}=C_{C W T, \text { in }}^{t},
\end{gathered}
$$

where $C_{C W T, \text { in }}^{t}$ and $C_{C W T, \text { out }}^{t}$ are the cold power input and output of the chilled water tank respectively, $C_{L B R, o u t}^{t}$ is the cold power output of the Lithium Bromide refrigeration units, $C_{\text {Space }}^{t}$ and $C_{\text {Refii }}^{t}$ are the space cooling load and refrigeration load respectively in the building CCHP system, the variable $C_{C W T \text {, in }}^{t}$ and $C_{C W T \text {,out }}^{t}$ meets the equipment constraint of (2).

4) The capacity and operation constraints

The capacity and operation constraints of the energy supply and storage equipment in building CCHP system are shown as follows.

For micro turbines

$$
P_{i}^{\min } \leq P_{i}^{\mathrm{t}} \leq P_{i}^{\max }, i \in n_{C H P} .
$$

For Lithium Bromide refrigeration units

$$
0 \leq H_{\mathrm{LBR}, \text { in }}^{\mathrm{t}} \leq H_{\mathrm{LBR}, \text { in }}^{\max } .
$$

For electrical heater

$$
0 \leq P_{E H}^{t} \leq P_{E H}^{\max }
$$

For storage devices:

$$
\begin{gathered}
0 \leq H_{\text {in }}^{\mathrm{t}} \leq H_{\text {in }}^{\max }, \\
0 \leq H_{\text {out }}^{\mathrm{t}} \leq H_{\text {out }}^{\max }, \\
S_{\text {stor }}^{\min } \leq S_{\text {stor }}^{\mathrm{t}} \leq S_{\text {stor }}^{\max },
\end{gathered}
$$

where $H_{\text {in }}^{t}$ and $H_{\text {out }}^{t}$ are the power input and output of the four kinds of storages respectively at the moment t. $H_{i n}^{\max }$ and $H_{\text {out }}^{\max }$ are the maximum value of power input and output of the storages respectively. $S_{\text {stor }}^{t}$ is the storage status of the four kinds of storage equipment, $S_{\text {stor }}^{\text {min }}$ and $S_{\text {stor }}^{\text {max }}$ are the minimum and maximum bound of the storage status.

\section{Solution Method for the Model}

Since there are various kinds of energy supply and storage equipment in the optimization model, large numbers of sparse matrix elements will occur when listing the constraints matrix and the solving process will become extremely long if global solution space searching algorithms like genetic algorithm or particle swarm optimization algorithm is used [16]. Interior point method is able to solve large scale nonlinear optimization problems quickly by making full use of the sparsity of its modified matrix. Since interior point method has the advantages of handling sparse matrix in solving the optimization model, this paper applies interior point method with Hessian matrix iteration to solve the model.

The standard form can be written as follows:

$$
\left\{\begin{array}{c}
\min f(x), \\
\text { s.t. } c(x) \leq 0, \\
c e q(x)=0, \\
A x \leq b, \\
A_{e q} x=b_{e q}, \\
l b \leq x \leq u b .
\end{array}\right.
$$

The solving process construct the Lagrange auxiliary function which meets the conditions of Karush-Kuhn-Tucker [17].

Through transformation of matrix in the modified function, $\mathrm{LDL}^{\mathrm{T}}$ factorization, backward substitution and correction, the problem can be solved when the iteration results meets the convergence condition.

\section{CASE StUdy}

The case studied is a building CCHP system located in the animation park of Sino-Singapore Tianjin Eco-City with the load in creativity exhibition building and the energy supply equipment in the animation park energy station. The energy supply and storage equipment include micro turbines, hot water tank, Lithium Bromide refrigeration units, chilled water tank, electrical heater, electrical heating storage tank, battery, and distributed solar system. The building CCHP system exchanges power with external power network, and the gas needed in the system is all bought from the municipal gas company considering that there is no gas production in the building CCHP system. The optimal economic dispatch model is coded using MATLAB R2014a, the parameters of the energy supply and storage equipment in the case are shown as Table I and Table II.

TABLE I. THE COEFFICIENTS OF ENERGY SUPPLY EQUIPMENT.
\begin{tabular}{|c|c|c|}
\hline Equipment & Parameter & Value \\
\hline $\begin{array}{c}\text { Capstone C } 1000 \\
\text { Micro Turbine } \\
\text { Systems }\end{array}$ & Maximum Power Output $P_{c 1000, \max }$ & $1000 \mathrm{~kW}$ \\
\cline { 2 - 3 } & Nominal Efficiency $\eta_{c 1000}$ & 0.33 \\
\hline $\begin{array}{c}\text { Lithium Bromide } \\
\text { refrigeration units }\end{array}$ & Maximum Power Input $P_{L B R, \max }$ & $200 \mathrm{~kW}$ \\
\hline Electrical Heater & Maximum Power Input $P_{E H, \max }$ & 1.2 \\
\hline External Network & Nominal Efficiency $C O P_{E H}$ & $200 \mathrm{~kW}$ \\
\hline $\begin{array}{c}\text { Distributed Solar } \\
\text { System }\end{array}$ & Maximum Power Exchange $P_{B u, \max }$ & $1800 \mathrm{~kW}$ \\
\hline
\end{tabular}

The day-ahead forecasting load curve of the creativity exhibition building in the building CCHP system is shown in Fig. 4. The system adopts TOU pricing shown in Table III and the natural gas prices is converted from $0.53 \$ / \mathrm{m}^{3}$ to $0.055 \$ / \mathrm{kW} \cdot \mathrm{h}$ with the gross heat value of $8571 \mathrm{kcal} / \mathrm{m}^{3}$. The 
optimal dispatch schedule of the energy station can be made by solving the proposed day-ahead optimal economic dispatch model and the results are shown in below.

\begin{tabular}{|c|c|c|c|c|}
\hline Parameter Equipment & $\begin{array}{c}\text { Lead } \\
\text { Acid } \\
\text { Battery }\end{array}$ & $\begin{array}{c}\text { Hot } \\
\text { Water } \\
\text { Tank }\end{array}$ & $\begin{array}{c}\text { Chilled } \\
\text { Water } \\
\text { Tank }\end{array}$ & $\begin{array}{c}\text { Electrical } \\
\text { Heating } \\
\text { Storage } \\
\text { Tank }\end{array}$ \\
\hline Charge Efficiency & 0.97 & 0.95 & 0.95 & 0.95 \\
\hline Discharge Efficiency & 0.97 & 0.95 & 0.95 & 0.95 \\
\hline $\begin{array}{c}\text { Maximum Charge } \\
\text { Rate }\end{array}$ & 0.2 & 0.2 & 0.2 & 0.2 \\
\hline $\begin{array}{c}\text { Maximum Discharge } \\
\text { Rate }\end{array}$ & 0.3 & 0.2 & 0.2 & 0.3 \\
\hline Self-Discharge Rate & 0.02 & 0.03 & 0.03 & 0.03 \\
\hline $\begin{array}{c}\text { Maximum State Of } \\
\text { Charge }\end{array}$ & 0.9 & 0.9 & 0.9 & 0.9 \\
\hline $\begin{array}{c}\text { Minimum State Of } \\
\text { Charge }\end{array}$ & 0.2 & 0.1 & 0.1 & 0.1 \\
\hline Capacity(kw·h) & 200 & 10000 & 2000 & 2000 \\
\hline
\end{tabular}

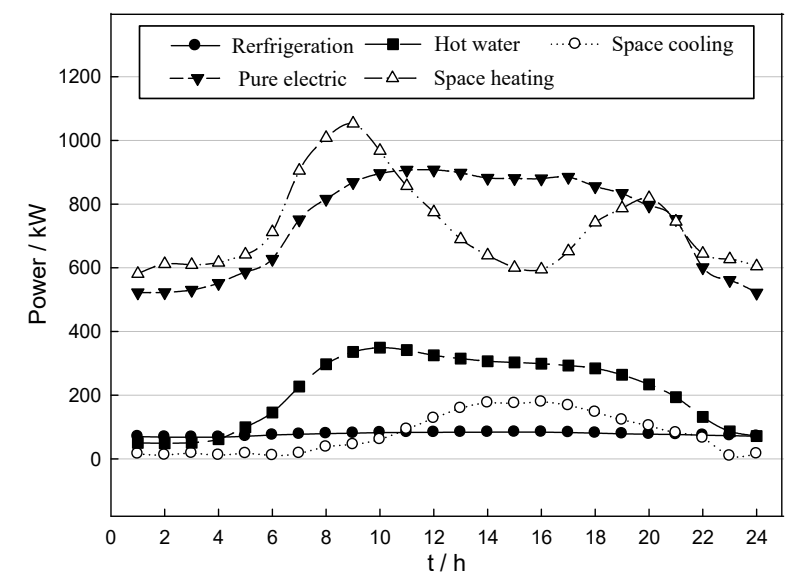

Fig. 4. Day-ahead forecasting load curve of the building within the system.

TABLE III. TIME OF USE PRICE.

\begin{tabular}{|c|c|c|}
\hline Time Period & Detail Time & Price (\$/Kwh) \\
\hline Peak & $9: 00-11: 00,19: 00-22: 00$ & 0.1353 \\
\hline Valley & $0: 00-7: 00,22: 00-24: 00$ & 0.0573 \\
\hline Intermediate & $7: 00-9: 00,11: 00-19: 00$ & 0.0952 \\
\hline
\end{tabular}

Figure 5 shows that the proposed OED schedule strategy could control the operation status of the energy supply equipment in the building CCHP system to achieve the goal of decreasing operation cost while keeping the electricity balance.

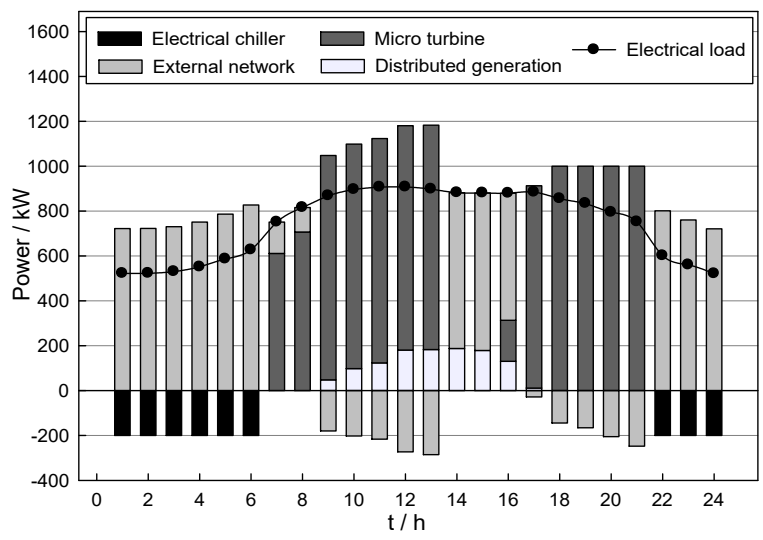

Fig. 5. Electricity balance curve by the optimal economic dispatch schedule.

Figure 6 shows that the proposed OED schedule strategy could control the storage status of the hot water storage tank fluctuating in large dynamic range by flexible charging and discharging according to the load demand in the whole operation period. Under the FEL schedule strategy, the storage status of the hot water tank exceeds $30 \%$ than the balance state in the operation period. To meet the requirement of the closed-loop control of the storage devices, the system is obliged to abandon $30 \%$ of the produced heat energy, resulting in a large degree of energy waste and economic losses. Under the FTL schedule strategy, the hot water tank storage does not fully play the role of peak load shifting, overall follow the trend of first charge then release. The storage status always remains at a low level, thus resulting in the waste of storage capacity.

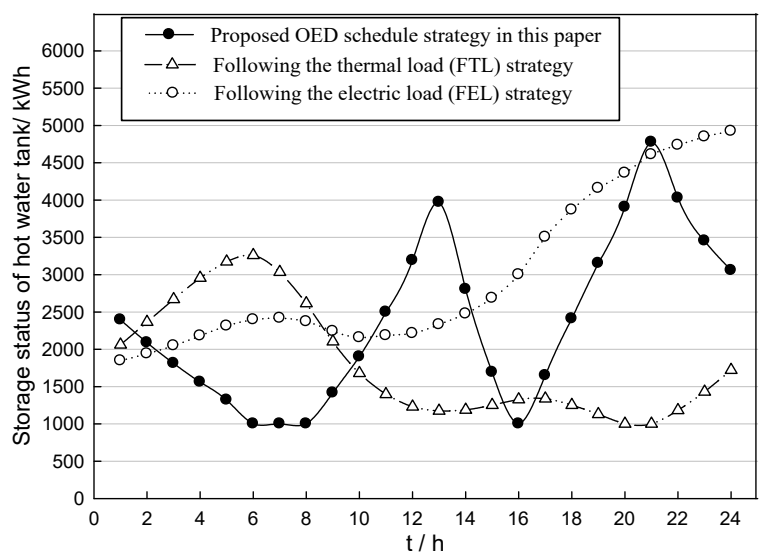

Fig. 6. Storage status of the hot water tank under different schedule strategies.

Figure 7 shows that the proposed OED schedule strategy could control the charging status of the chilled water storage tank flexibly, other traditional schedule strategy only possess the means of charge and discharge consistently for a long time. The proposed OED schedule strategy could achieve better control effect while occupied less $35 \%$ capacity of the storage than FEL and FTL schedule strategy.

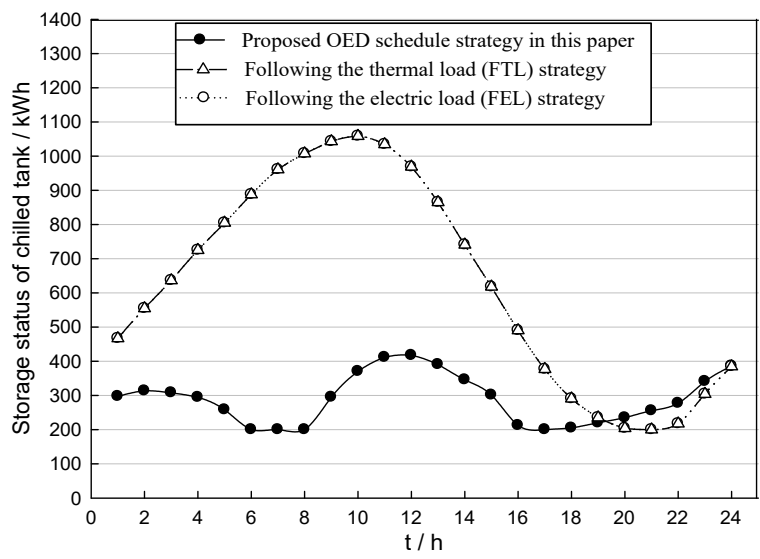

Fig. 7. Storage status of the chilled water tank under different schedule strategies.

Figure 8(a) shows that the proposed OED schedule strategy could control the charge and discharge power of the electrical heater storage device according to the TOU price than FEL and FTL schedule strategy. Figure 8(b) shows that at night, electrical heater charges the storage tank, gradually the storage status of the electrical heater storage tank reaches the peak value; during the daytime, electrical heater storage tank 
release the heat energy to meet the need of thermal load.
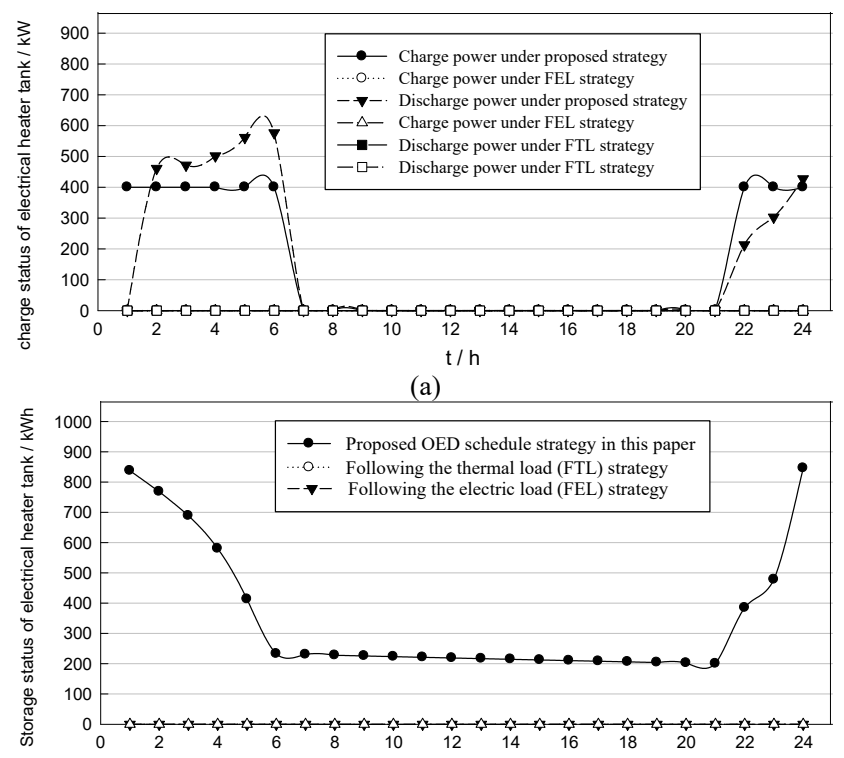

(b)

Fig. 8. Charge and storage status of the electrical heater storage tank under different schedule strategies: a) charge status under different schedule strategies; b) storage status under different schedule strategies.

TABLE IV. DAILY OPERATION COST OF THE BUILDING CCHP SYSTEM UNDER DIFFERENT SCHEDULE STRATEGIES.

\begin{tabular}{|c|c|}
\hline Schedule strategy & Daily operation cost (\$) \\
\hline Proposed OED strategy & 1928.84 \\
\hline Following the thermal load (FTL) strategy & 2264.89 \\
\hline Following the electric load (FEL) strategy & 2616.32 \\
\hline
\end{tabular}

Table IV shows the daily operation cost of the building CCHP system under different schedule strategies. The daily operation cost under the proposed OED schedule strategy is 1928.84 \$. Under the FTL strategy, the micro turbine gives priority to satisfy the thermal load in the building CCHP system, the unbalance of electricity is bought from the public network and the daily operation cost is 2264.89 \$. Under the FEL strategy, the micro turbine gives priority to satisfy the electricity load in the building CCHP system and the amount of produced heat energy exceeds the thermal load, which results in $30 \%$ heat energy waste, the daily operation cost is $2616.32 \$$. After adopting the proposed OED schedule strategy, the daily operation cost decreases $14.84 \%$ and $26.28 \%$ than the other two schedule strategies respectively.

\section{CONCLUSIONS}

This paper focus on the problem of making optimal economic dispatch schedule for building CCHP system and establishes a day-ahead optimal economic dispatch model based on centralized energy storage infrastructure which can increase the system's instantaneous power output. In the model, the loads are met by the centralized energy storage equipment directly instead of the energy supply equipment, and the storage equipment are charged by varieties of energy supply devices in the energy station of the building CCHP system. A case study shows that the proposed OED schedule strategy could reduce $14.84 \%$ and $26.28 \%$ daily operation cost than the other two schedule strategies, which verifies the effectiveness of the proposed OED schedule strategy.

\section{REFERENCES}

[1] Z. Li, W. Wu, M. Shahidehpour, J. Wang, B. Zhang, "Combined heat and power dispatch considering pipeline energy storage of district heating network", IEEE Trans. Sustainable Energy, vol. 7, no. 1, pp. 12-22, 2015. DOI: 10.1109/TSTE.2015.2467383.

[2] Mingxi Liu, Yang Shi, Fang Fang, "Load forecasting and operation strategy design for CCHP systems using forecasted loads", IEEE Trans. Control Systems Technology, vol. 23, pp. 1672-1684, 2015. DOI: 10.1109/TCST.2014.2381157.

[3] H. Yang, T. Xiong, J. Qiu, et al., "Optimal operation of DES/CCHP based regional multi-energy prosumer with demand response", Applied Energy, vol. 167, pp. 353-365, 2016. DOI: 10.1016/j.apenergy.2015. 11.022 .

[4] M. Stadler, M. Kloess, M. Groissb Ck, G. Cardoso, R. Sharma, "Electric storage in California's commercial buildings", Applied Energy, vol. 104, pp. 711-722, 2013. DOI: 10.1016/j.apenergy. 2012.11.033.

[5] Z. Luo, Z. Wang, W. Gu, Y. Tang, C. Xu, "A two-stage energy management strategy for CCHP microgrid considering house characteristics", in Proc. IEEE Power \& Energy Society General Meeting, 2015, pp. 1-5. DOI: 10.1109/PESGM.2015.7285845.

[6] Z. X. Yuan, Z. X. Jing, R. X. Hu, Q. H. Wu, "Operation optimization of CCHP-type microgrid considering units' part-load characteristics", in Proc. IEEE Innovative Smart Grid Technologies-Asia (ISGT ASIA 2015), 2015, pp. 1-7. DOI: 10.1109/ISGT-Asia.2015.7387084.

[7] Z. Bao, Q. Zhou, Z. Yang, Q. Yang, L. Xu, T. Wu, "A multi time-scale and multi energy-type coordinated microgrid scheduling solution-part I: model and methodology", IEEE Trans. on Power Systems, vol. 30, pp. 2257-2266, 2015. DOI: 10.1109/TPWRS.2014.2367127.

[8] Z. Bao, Q. Zhou, Z. Yang, Q. Yang, L. Xu, T. Wu, "A multi time-scale and multi energy-type coordinated microgrid scheduling solution-part II: optimization algorithm and case studies", IEEE Trans. Power Systems, vol. 30, pp. 2267-2277, 2015. DOI: 10.1109/TPWRS.2014.2367124.

[9] Gao P, Dai Y, Tong Y W, et al., "Energy matching and optimization analysis of waste to energy CCHP (combined cooling, heating and power) system with exergy and energy level", Energy, vol. 79, pp. 522-535, 2015. DOI: 10.1016/j.energy.2014.11.050.

[10] C. Y. Zheng, J. Y. Wu, X. Q. Zhai, et al., "A novel thermal storage strategy for CCHP system based on energy demands and state of storage tank", International Journal of Electrical Power \& Energy Systems, vol. 85, pp. 117-129, 2017. DOI: 10.1016/j.ijepes.2016.08.008.

[11] H. Zhang, D. Zhao, C. Gu, F. Li, "Bilevel economic operation of distribution networks with microgrid integration", Journal of Renewable and Sustainable Energy, vol. 7, no. 2, pp. 23-120, 2015. DOI: $10.1063 / 1.4917556$.

[12] K. Thu, B. B. Saha, K. J. Chua, et al., "Thermodynamic analysis on the part-load performance of a microturbine system for micro/mini-CHP applications", Applied Energy, vol. 178, pp. 600-608, 2016. DOI: 10.1016/j.apenergy.2016.06.106.

[13] M. A. Meybodi, M. Behnia, "A study on the optimum arrangement of prime movers in small scale microturbine-based CHP systems", Applied Thermal Engineering, vol. 48, pp. 122-135, 2012. DOI: 10.1016/j.applthermaleng.2012.05.013.

[14] A. Zeng, Q. Xu, M. Ding, K. Yukita, K. Ichiyanagi, "A classification control strategy for energy storage system in microgrid", IEEJ Transactions on Electrical and Electronic Engineering, vol. 10, pp. 396-403, 2015. DOI: 10.1002/tee.22099.

[15] A. Zeng, X. Qing-shan, D. Mao-sheng, L. Zhang-sui, X. Xiao-hui, "Effect of wind- storage complementary microgrid on reliability of power distribution network", Journal of South China University of Technology (Natural Science Edition), vol. 42, pp. 26-33, 2014. DOI: 10.3969/j.issn.1000-565X.2014.04.005.

[16] C.-F. Juang, C.-M. Hsiao, C.-H. Hsu, "Hierarchical cluster-based multispecies particle swarm optimization for fuzzy system optimization", IEEE Trans. Fuzzy Systems, vol. 18, no. 1, pp. 14-26, 2010. DOI: 10.1109/TFUZZ.2009.2034529.

[17] Xu Qingshan, Zeng Aidong, Wang Kai, et al., "Day-ahead optimized economic dispatching for combined cooling, heating and power in micro energy-grid based on Hessian interior point method", Power System Technology, vol. 40, no. 6, pp. 1657-1665, 2016. DOI: 10.13335/j.1000-3673.pst.2016.06.008. 